\title{
Adaptação do Comportamento Animal e Mundos Emergentes
}

\author{
Michel Jean Dubois ${ }^{1}$ \\ Universidade Federal do Pará \\ Yvonnick Le Pendu \\ Universidade Federal do Pará \\ Jean-François Gerard ${ }^{2}$ \\ Institut de Recherche sur les Grands Mammiferes, França \\ Elineuza Sampaio \\ Universidade Federal do Pará
}

\begin{abstract}
Resumo
Discutimos as implicações da noção de adaptação que é uma noção chave para a teoria da evolução clássica. Em lugar de obstinar-se em considerar os organismos como coleção de traços adaptados, propomos buscar estudar a evolução por meio de um quadro teórico onde prevalece uma outra ontologia que destaca o fato de que os organismos e as circunstâncias são totalmente integrados. A etapa preliminar necessária para esta reconsideração consiste em passar de uma lógica prescritiva para uma lógica proscritiva. Isto é, da idéia de que tudo que não é permitido, é proibido; à idéia que o que não é proibido, é permitido. Propomos que a idéia de que os sistemas vivos especificam o mundo no qual eles vivem pode modificar nossa maneira de encarar os processos adaptativos.

Palavras-chave: Adaptação; estrutura; organização; perturbação; viabilidade.
\end{abstract}

Adaptation of Animal Behavior and Emergent Worlds

\begin{abstract}
We discuss the implications of the concept of adaptation, which is a key notion for the classical theory of evolution. Instead of persisting to consider the organisms as a collection of adapted traits, we propose to study evolution by means of a theoretical frame based on another ontology considering the organisms and the circumstances as totally integrated. The necessary preliminary stage for this reconsideration consists in passing from a prescriptive logic to a proscriptive logic, i.e., from the idea that everything that is not allowed is forbidden, to the idea that what is not forbidden is allowed. The consideration that the living systems specify the world in which they live can modify our way to face adaptive processes.

Keywords: Adaptation; structure; organization; disturbance; viability.
\end{abstract}

A idéia de adaptação pressupõe na sua acepção lógica que uma coisa esteja adaptada a uma outra que é exterior à ela: A está adaptado a B. A teoria da evolução pela seleção natural estabelece que as novas espécies nascem de espécies ancestrais da seguinte maneira: indivíduos numa população determinada herdam traços morfológicos, fisiológicos... vantajosos em termo de sobrevivência. Os indivíduos que se adaptam da melhor maneira possível às condições ambientais deixam em média mais descendentes que os concorrentes. Os traços vantajosos assim selecionados tornam-se mais freqüentes nas populações podendo vir a ser majoritários.

$\mathrm{O}$ fato que quase todos os caracteres morfológicos ou comportamentais de um animal devem corresponder

\footnotetext{
${ }^{1}$ Endereço para correspondência: Departamento de Psicologia Experimental, Universidade Federal do Pará, 66075-150, Belém, Pará.

${ }^{2}$ Endereço para correspondência: Institut de Recherche sur les Grands Mammifères, INRA, CRA Toulouse, BP27, 31326 Castanet-Tolosan, França.
}

a uma adaptação particular que foi selecionada conduz a uma atomização dos organismos. Por exemplo, é comum dizer que os dentes da onça e a sua rapidez são adaptações para a caça e o regime carnívoro, que as orelhas dos elefantes são adaptação para a termoregulação do corpo, que as características da pelagem ou plumagem (padronagens e cores) dos animais traduzem uma adaptação seja para aproximar-se das presas, escapar dos predadores ou, entre outras adaptações possíveis, para atrair um parceiro sexual. Do mesmo jeito, os olhos do veado galheiro (Odocoileus virginianus) e as suas elegantes patas representam adaptações para uma fuga eficaz. Ora, o valor adaptativo de cada parte de um organismo é, muitas vezes, postulado a priori. Devido a isso, as explicações adaptativas variam de um pesquisador a um outro ou de uma época a outra. Por exemplo, a proliferação dos ungulados nas estepes é explicado pelo fato que certas características anatômicas particulares, conferindo a aptidão a corridas rápidas, foram 
gradualmente selecionadas por serem vantajosas para escapar dos carnívoros da época (Dawkins, 1995). Mas esta história adaptativa foi superada pela descoberta recente de que os carnívoros evoluíram cerca de 20 milhões de anos depois dos ungulados. Portanto não são os carnívoros por suas perseguições (pressões seletivas) que têm moldado as pernas adaptadas dos ungulados (Janis \& Wilhem, 1993).

Numerosas críticas desse tipo foram feitas à noção de adaptação a um meio ambiente seletivo, o que levou vários pesquisadores a proporem sérias reconsiderações a atual teoria da evolução vista como programadora de comportamentos adaptativos (Gerard, Dubois, Le Pendu, Guilhem \& Mechkour, 1997; Goodwin, 1994; Gould \& Lewontin, 1979; Kauffman, 1993; Lewontin, 1983; Maturana \& Varela, 1987; Raup, 1992; Varela, Thompson \& Rosch, 1991).

Entre elas vamos destacar a crítica formulada por Varela e colaboradores (1991). A perspectiva por eles adotada propõe que a etapa preliminar necessária para reconsiderar a noção de adaptação consiste em passar de uma lógica prescritiva para uma lógica proscritiva. Isto é, passar da idéia de que tudo que não é permitido é proibido, à idéia que o que não é proibido é permitido. $\mathrm{Na}$ situação prescritiva, o organismo é forçado a fazer o que ele está fazendo e nada mais. Na situação proscritiva, o organismo tem a potencialidade de adotar numerosas possibilidades segundo as situações, algumas vezes criadas por ele mesmo, salvo algumas incoerências. No contexto da evolução, a lógica proscritiva consiste em renunciar à idéia de que a seleção define tudo e guia a função de melhora do valor adaptativo. Nesta situação, os mecanismos seletivos clássicos ficam ativos, mas unicamente para afastar os elementos que são radicalmente contrários à sobrevivência e reprodução. Esta orientação proscritiva muda nossa atenção na direção da fantástica diversidade das estruturas biológicas e procura descobrir como elas se organizam para fornecer o substrato de vários caminhos viáveis, mas não otimizados.

Quando admitimos que a seleção é somente um filtro operando sobre a sobrevivência global, a análise não é mais centrada sobre os traços mas sobre as formas de organização adotadas pelos organismos. Uma metáfora desta abordagem seria aquela do bricolage (Jacob, 1981), isto é, o funcionamento do organismo não é a realização de um plano ideal, mas "simplesmente" a realização de um possível entre vários outros.

\section{Mundos Emergentes}

O mundo dos seres vivos não pára de se modificar: a repartição e o relevo dos continentes, a meteorologia planetária que é intrinsecamente caótica. As flutuações climáticas acompanham-se de variações nas quantidades dos diferentes estados da água. O nível do mar muda drasticamente, reduzindo as partes continentais, e paralelamente o gelo das regiões polares invadem periodicamente baixas latitudes, ou, ao contrário, quase desaparecem. Essas modificações espetaculares põem a questão de saber como os seres vivos conseguem se manter em tais condições de mudanças.

Segundo a teoria neo-darwinista, as espécies adaptamse às flutuações do meio ambiente graças ao processo seletivo que intervê dentro de cada espécie. Nesta perspectiva, as linhagens que desaparecem seriam aquelas cujo polimorfismo genético seria limitado demais para permitir adaptar-se aos problemas postos pelo meio ambiente (van Valen, 1973). Mas devemos notar o fato de que um grande número de linhagens de organismos persistem e têm conservado uma mesma morfologia apesar das modificações ocorridas no globo (Gould \& Eldredge, 1993; Raup, 1992; Vrba, 1992).

Fica difícil, nestas condições, afirmar que os seres vivos sobrevivem às flutuações do meio ambiente graças às suas capacidades para evoluir. De maneira quase sistemática, a teoria neodarwinista ignora os processos que intervêem na escala da geração. $\mathrm{O}$ neodarwinismo passa classicamente das freqüências de genes aos fenótipos e aos organismos capazes de reprodução. A etapa do desenvolvimento que permite a ligação entre o nascimento e a idade adulta é superficialmente mencionada quando ela pode ser essencial como veremos a seguir.

Pois, esta teoria ignora um ponto fundamental, a saber, que os sistemas vivos, longe de serem simplesmente confrontados com uma realidade exterior, atuam e especificam o mundo e as propriedades do mundo no qual eles vivem. Estudos de Held e Hein (1963) e Held (1965) ilustram este ponto. Nesta experiência, foram criados vários gatinhos na escuridão. Eles estavam expostos à luz somente em condições controladas. Um primeiro grupo de animais foi autorizado a circular quase normalmente, mas eles estavam atrelados a um tipo de carroça contendo o segundo grupo de animais. Os dois grupos dividiam então a mesma experiência visual, mas o segundo grupo era inteiramente passivo. Quando os animais foram expostos à luz em condições normais, depois de algumas semanas do tratamento anterior, os gatinhos do primeiro grupo comportavam-se normalmente, mas os que tinham sido carregados pareciam que estavam cegos: eles batiam-se contra os objetos e caíam. O que podemos reter desta experiência é a idéia que ver objetos não consiste apenas em extrair 
deles traços visuais, mas guiar visualmente a ação dirigida na direção deles. Não há percepção sem ação no real, sem movimento, sem comportamento efetivo que especifica, configura o mundo.

Essa idéia de que os organismos especificam o mundo no qual eles vivem pode parecer estranha porque somos condicionados a considerar que o universo é dotado de propriedades intrínsecas com as quais os organismos devem interagir para conseguir sobreviver. Entretanto é claro que os sistemas vivos especificam, eles mesmos, as condições ambientais que são compatíveis com a sua existência. Assim poderíamos transformar o conhecido aforismo de Dobzhansky (1973), que dizia que "nada tem sentido na biologia salvo à luz da evolução", em um "nada tem sentido no meio ambiente salvo à luz de um sistema vivo". Os sons, os odores são manifestações fenomenais que não existem em si, mas relativamente a um sujeito cognitivo que vai corporificá-las nas situações vividas. As estruturas de um sistema vivo se alteram de uma tal forma que ele adota uma conduta adequada que não se formalizava antes. O organismo que "habita" um meio e que opera de acordo com suas necessidades e potencialidades passa por uma contínua mudança ou deriva estrutural viável (Varela, 1979).

O que o observador descreve como sendo uma única configuração ambiental terá, muitas vezes, vários efeitos em função do sistema biológico considerado porque cada sistema opera distinções autônomas em relação às ações desenvolvidas. Nas formigas, a presença simultânea de várias fontes de comida traduz-se por uma equirepartição dos indivíduos em uma espécie e à escolha de uma fonte preferencial em uma outra espécie (Fresneau, 1985). Alguns pássaros (Turdus philomelos) são sensíveis a pequenas pedras para quebrar a casca do caracol quando outros do mesmo gênero (T. merula) são insensíveis (Gerard e cols., 1997). Da mesma forma, o macaco prego pode tornar-se sensível às pedras e conseguir quebrar castanhas quando outros macacos nunca tentarão usar esses elementos do meio (Dubois, Sampaio, Gerard, Quenette \& Muniz, 2000). Na realidade, o organismo especifica o que ele admite como interação e é transparente para outras coisas. Vocês não entendem o que escrevemos quando uso uma linguagem desconhecida: Hanna vefsidutöflu med $i$ rö̈um, porque vocês especificam quais as letras que compreendem.

Reciprocamente, configurações ambientais que descrevemos como distintas podem induzir um mesmo fenômeno num sistema biológico. No domínio da percepção visual humana, isso se traduz pelo fato de que espectros luminosos diferentes correspondem à mesma cor percebida (Varela, 1979). Portanto, a experiência

Psicologia: Reflexão e Crítica, 2001, 14(3), pp. 581-587 cromática deixa de ser uma representação do mundo e passa a ser uma configuração do mundo. $\mathrm{Na}$ embriologia, este fenômeno conduz ao fato que estímulos variados não específicos podem induzir a uma mesma diferenciação (Goodwin, 1994). Isso acontece porque o organismo é uma unidade que opera conservando a organização, como uma rede coerente de produções de componentes na qual estes produzem o sistema circular que os produz. As alterações que uma máquina qualquer pode sofrer em seus aspectos dinâmicos não são determinadas pelo ambiente exterior, mas por sua organização e plasticidade estrutural. O que acontece com uma máquina de lavar, por exemplo, depende da maneira como ela é montada. Quando apertamos um botão - ela molha, lava, enxágua, toca música para as mais sofisticadas, mas ela não vai decolar como poderia fazer um foguete porque cada organização tem restrições. No caso de um organismo, as interações a que o organismo é submetido conseguem apenas acionar mudanças, mas não as determinam. Não se dá instruções a um sistema definido por uma determinada organização, não se especifica o que deve acontecer no sistema. Se a ontogenia desenvolve-se de maneira viável e o organismo vive até a reprodução, ela é realizada pela correspondência invariável com o meio, o que chamamos acoplamento estrutural. Sua estrutura está mudando e o meio está mudando, mas a coerência com o meio é mantida. Em cada reprodução conseguida, um organismo não transmite somente genes como tal, mas também um meio ambiente (nicho ecológico), de tal maneira que estas entidades poderiam se tornar efetivamente genes (Varela e cols., 1991). Consideramos os traços do meio ambiente tais como a luz do sol ou o oxigênio como independentes do organismo somente porque nosso quadro de referência é relativo. $\mathrm{O}$ ar se torna um substrato que permite a atividade de voar a partir do momento onde ele é habitado por pássaros; mas reciprocamente, não podemos nos referir aos pássaros sem referirmo-nos ao fato que são animais que voam no ar (Stewart, 1993). Segundo Merleau-Ponty (1995), a relação entre o mundo e o organismo é como um rastro que não está ligado a um barco.

Muitas mudanças são potencialmente possíveis e a seleção de uma delas será feita em função do tipo específico de coerência estrutural que a unidade considerada apresenta, em um processo de emendas ininterrupto. Se não fosse uma invariável, a adaptação cessaria e o organismo se desintegraria. A invariável da adaptação é uma coerência estrutural, significando que a estrutura do sistema pode ser descrita de forma dinâmica. Os sistemas biológicos especificam quais perturbações ambientais terão sobre eles um efeito durável e qual será 
este efeito. Devemos então aceitar a possibilidade que os organismos fazem emergir o mundo no qual eles vivem, dando uma significação a certas perturbações ambientais. Isto não quer dizer que a seleção natural não influencia as propriedades de um sistema vivo durante a sua historia filogenética : quando elas são viáveis, as significações que um sistema biológico faz emergir podem produzir variações, pelo menos parcialmente herdáveis, suscetíveis de se transmitir mais rapidamente que outras. Um sistema vivo não possui outro meio ambiente se não o mundo que ele próprio especifica. Assim, seria ele mesmo a origem das pressões seletivas que podem atuar sobre a variabilidade das propriedades que o definem.

Vamos ilustrar este ponto com alguns exemplos fornecidos pelo comportamento animal.

\section{Modificação Espontânea da Alimentação em Pássaros}

Este exemplo famoso na etologia (Hinde \& Fisher, 1951), é um caso de inovação alimentar em um passarinho. $\mathrm{Na}$ Inglaterra, o leite começou a ser distribuído nas casas a partir dos anos 20. Alguns anos depois, duas espécies de passarinhos (Parus caeruleus e Parus major) tinham adquirido o hábito de abrir as garrafas para consumir o conteúdo.

Em vez de pressupor elaboradas capacidades cognitivas, podemos explicar a emergência deste comportamento, que pode ter conseqüências sobre a sobrevivência, com base em um conjunto de atos simples. Primeiro, esses passarinhos têm o hábito de inspecionar uma grande variedade de objetos, que são martelados com golpes de bico. Essa atividade é certamente estimulada pelo som que produz o objeto martelado e pelas possibilidades de deformação do objeto martelado. Por outro lado, os objetos que podem ser segurados no bico são sistematicamente puxados. Assim, algumas características comportamentais específicas desses passarinhos levaram a uma operação de distinção e à emergência das garrafas de leite (que não são garrafas de leite do ponto de vista do passarinho) como elementos relevantes do ambiente em toda a Inglaterra, e, pelo menos a longo prazo, a um processo de evolução autônomo da forma do bico, por exemplo (Gerard e cols., 1997). Devemos então ressaltar que um conjunto de atos simples específicos da biologia da espécie e um processo de reforçamento ligado às conseqüências desses atos são elementos suficientes para explicar alguns casos de inovações comportamentais (Collier, Hirsch \& Kanarek, 1977; Staddon, 1980)

\section{Comportamento de Limpeza da Comida em Macacos}

No início dos anos cinqüenta, numa pequena ilha foi observado um macaco japonês (Macaca fuscata) limpando batatas doces na água antes de comê-las (Kawai, 1965). Este comportamento inovador que se espalhou nesta comunidade animal ao longo dos anos criou vários debates relativos a transmissão de tradições culturais por imitação (Lefebvre, 1995; McGrew, 1998; Whiten, 2000). Entretanto, as experimentações conduzidas por Visalberghi e Fragaszy (1990) mostraram que este comportamento emerge facilmente depois de algumas horas em diversas espécies de macacos se a água é de acesso imediato. Quando a água é bastante afastada, o número de macacos apresentando este comportamento diminui drasticamente. O comportamento de limpeza parece ser descoberto por acaso pelos indivíduos mais curiosos durante atividades exploratórias onde os mesmos combinam elementos do ambiente. Além disso, nenhum indício de imitação (que consiste na habilidade de aprender rapidamente um novo comportamento observando o comportamento de um outro indivíduo) foi observado, indicando que os sujeitos atuam e aprendem independentemente uns dos outros. O crescimento do número de modelos potenciais podendo ser imitado não aumenta a difusão do comportamento.

Mais parcimoniosamente, os contextos sociais criados pelos inovadores constituem boas oportunidades, devido aos processos estimulantes de ordem social e espacial, para a descoberta de novos comportamentos por um fenômeno de tentativa e erro. A presença de limpadores é importante porque ela estimula o interesse pela água, o acesso a pedacinhos de comida e os comportamentos de brincadeira e exploração que podem levar à emergência do comportamento, que uma vez efetivado vai tomar sentido na vivência dos animais. Uma outra observação que merece ser feita relativa a este comportamento de limpeza é que o termo limparimplica a intenção de limpar. Nesta perspectiva deveríamos verificar (a) que só os alimentos limpos são consumidos e (b) um elemento já limpo não é limpo de novo. Porém, as experimentações e observações críticas feitas sobre os próprios macacos japoneses foram incapazes de confirmar esta intenção de limpar e deveríamos escolher um outro nome para falar deste fenômeno, como é o caso de numerosos outros comportamentos exibidos pelos animais (Dubois, Le Pendu, Siciliano \& Moinard, 1997). Ainda neste caso de inovação, algumas características comportamentais específicas levaram a uma operação de distinção e à emergência da água como elemento relevante do ambiente, e, pelo menos a longo 
prazo, à um processo de evolução de um comportamento que pode se tornar precioso.

\section{Formação de Grupos em Ungulados}

Os organismos não são os únicos sistemas biológicos que dão uma significação a algumas flutuações ambientais. Observamos o mesmo fenômeno quando se trata de um conjunto de indivíduos em interação (Maturana \& Varela, 1987). O exemplo do tamanho dos grupos de corzos (Capreolus capreolus), que é um ungulado europeu do mesmo porte que o veado campeiro sul-americano, é nesta perspectiva muito ilustrativo. Este animal é geralmente considerado como florestal em razão de várias características fisiológicas, morfológicas e comportamentais. Apesar de parecer particularmente adaptado ao meio da mata fechada, este ungulado, considerado até então como solitário (suposta estratégia adaptativa antipredadora no contexto da mata fechada), começou desde alguns anos a colonizar os meios abertos. O ponto mais interessante deste fenômeno é que foi observado um crescimento do tamanho dos grupos que são ainda mais importantes quando o meio é mais aberto.

Este crescimento do tamanho dos grupos, na ausência de qualquer predador, não implica que o comportamento dos animais foi modificado com a abertura do meio. Como em muitos ungulados e primatas, os grupos se formam e se deslocam freqüentemente. Isso quer dizer que as freqüências dos tamanhos dos grupos observados em uma população correspondem a um equilíbrio dinâmico, emergindo das fusões e fragmentações que remodelam continuamente o número e o tamanho dos grupos. Dois grupos não podem encontrar-se quando os animais não podem perceber-se. Devido a isso, todo crescimento da distância com a qual os animais podem perceber-se aumenta a freqüência das fusões e então o tamanho médio dos grupos. Em outras palavras, o processo que provoca o tamanho dos grupos nas populações de corzo faz da abertura do meio uma propriedade relevante do meio ambiente (Gerard e cols., 1997). Podemos então avançar que as formas dos agrupamentos observados, como eles organizam-se, estão ligadas à dinâmica de regras locais caracterizando o funcionamento do corzo quando sofrendo uma perturbação deste tipo.

É óbvio que a fim de compreendermos o tipo de estrutura social que estamos registrando devemos observar as regras específicas atuando no funcionamento dos indivíduos e não apenas os fatores exteriores, supostamente determinantes, que os atingem. A percepção do mundo do corzo tem mais a ver com a forma como o sistema é organizado. E, acima de tudo,

Psicologia: Reflexão e Crítica, 2001, 14(3), pp. 581-587 com a forma como ele se identifica, no sentido de que são suas características, isto é, este animal se agrupa mais quando ele tem a possibilidade de perceber o outro, que são a chave para compreender o que vai acontecer com ele. Assim, neste caso a abertura do meio ambiente se torna uma perturbação relevante na medida em que o processo de agrupamento natural no corzo é mais recrutado. Em outras palavras, entendemos o sistema corzo como sendo um agrupamento de estruturas, ativo e auto-regulável, capaz de informar seu meio ambiente dentro de um universo e através de um histórico de ligação estrutural com ele.

Para unidades autônomas como os seres vivos, as perturbações não podem atuar como informações a serem processadas. Ao contrário, dizemos que o sistema tem uma clausura operacional, podendo ser concebido com um mundo próprio (Umwelt, von Uexküll, 1956), porque ele se baseia essencialmente sobre coerências internas capazes de especificar um universo relevante que não é um universo adaptativo no sentido prescritivo.

\section{Conclusões}

Se os três exemplos que acabam de ser apresentados ilustram como um sistema biológico faz emergir o seu mundo, eles destacam também um ponto importante relativo ao futuro dos sistemas vivos na escada da filogênese. Esses exemplos, que são fenômenos ligados a distinções efetuadas pelos próprios organismos, mostram que um sistema biológico sem propriamente adaptar-se, sem modificar o seu funcionamento, pode fazer emergir significações viáveis quando o meio ambiente está se modificando. Entretanto, as significações dadas não são sempre positivas, e há exemplos onde uma modificação do meio ambiente pode ser interpretada de maneira negativa. Poderei citar o exemplo das tartarugas marinhas que se sufocam depois de ingerir sacolas de plásticos que se parecem com as medusas (Balazs, 1985; Mrosovsky, 1981).

Estas diferentes possibilidades merecem atrair nossa atenção porque elas condicionam, desde que a vida existe, a persistência ou a extinção dos sistemas biológicos. É verdade que o mundo conhece continuamente mudanças mas as modificações do meio, virgens de todo sentido intrínseco, podem afetar os sistemas vivos somente quando eles fazem emergir significações ligadas a essas modificações. Assim, as formas de vida perduram ou se apagam em razão de sua insensibilidade a algumas modificações, e do sentido, viável ou nefasto, que elas dão as outras modificações. A tomada em consideração deste fenômeno muda fundamentalmente nossa maneira 
de compreender as relações entre os sistemas biológicos e o meio ambiente. Do mesmo jeito, ela modifica radicalmente nossa maneira de interpretar a história filogenética dos seres vivos. Na teoria neodarwinista, o meio ambiente é uma realidade exterior e flutuante que os sistemas vivos devem enfrentar. Eles devem obrigatoriamente adaptar-se ou desaparecer. A lógica é muito diferente quando tomamos em consideração a capacidade dos sistemas biológicos de fazer emergir seus mundos. As linhagens que persistem não são aquelas que a seleção natural consegue otimizar, porque as razões fundamentais que condicionam a persistência ou a extinção dos sistemas vivos são a sua insensibilidade a algumas modificações e o sentido, positivo ou negativo, que eles dão a outras. De um outro lado, não poderia haver adaptação a uma realidade exterior porque os fenômenos de radiações evolutivas, que se produzem algumas vezes em seguida a algumas modificações do meio ambiente, serão sempre a conseqüência das significações que os sistemas vivos fazem emergir. Devido a isso, os sistemas vivos aparecem não como objetos moldados por uma realidade exterior independente deles mesmos, mas como os atores fundamentais de sua própria evolução.

Nesta perspectiva, não é uma questão de sobrevivência do mais apto, mas uma questão de sobrevivência da adaptação. Não é a otimização o ponto central, mas a preservação da adaptação: um traçado de mudanças estruturais de uma linhagem que seja congruente com as mudanças em seu meio ambiente. Maturana e Varela (1987) chamam de deriva natural esta ótica da evolução centrada na preservação da adaptação como uma condição mínima. Um barco a deriva é um barco que não têm direção, nem remo, nem vela. Se você está neste barco quando não tem possibilidade de controlar a sua trajetória, então você está à deriva. Esta deriva continua mesmo se as correntes sejam contrárias, mesmo que você sofra vários danos. O que importa é que o barco, mesmo deformado, permanece um barco e fica flutuando. Entretanto, se o barco encontra um recife, ele vai se quebrar, então você não estará mais em deriva. A ontogênese é uma deriva de mudanças estruturais do organismo que dura tanto quanto as condições de conservação da organização são mantidas.

A maior diferença que vemos nesta reconsideração está relacionada com a noção de acoplamento estrutural com um meio. Segundo o ponto de vista clássico, o meio ambiente no qual os organismos evoluem e que eles conhecem é dado, fixo e único. Isto é, há uma realidade externa a qual os organismos devem adaptar-se. Mas não podemos conservar esta avaliação de um meio ambiente independente do organismo porque um meio não pode ser separado do que são os organismos nem do que eles fazem. O meio ambiente não existe lá fora como um terreno de aterrissagem onde os organismos cairiam de pára-quedas. Ao contrário, os seres vivos e seus respectivos ambientes situam-se numa relação de especificação mútua, ou, ainda, numa relação de co-determinação.

O que podemos descrever em termos de regularidades ambientais não consiste em traços exteriores internalizados, como o cognitivismo representacional (Gallistel, 1993; Johnston, 1982) e a visão adaptacionista (Krebs \& Davies, 1981) supõem. Aquelas são o resultado de uma história conjunta desenvolvida a partir de uma longa história de co-determinação. Como foi dito por Lewontin (1983), o organismo é no mesmo momento sujeito e objeto da evolução. Esta deriva poderia ser vista como a ontogênese do andar no ser humano, desde o desenvolvimento embrionário dos membros, seguida pela difícil aprendizagem do andar pela criancinha até a corporificação deste modo de ser ao mundo no adulto, manifestando-se nas acomodações inconscientes do andar cotidiano e dos acontecimentos variados como saltos, caídas, corridas, quedas, etc. Observamos nesta metáfora como uma deriva natural se mantém por um processo viável de mudanças contínuas até que a organização não possa ser conservada.

\section{Referências}

Balazs, G. H. (1985). Impact of ocean debris on marine turtles: Entanglement and ingestion. Em R.S. Shomura \& H. O. Yoshida (Orgs.), Proceedings of the. workshop on the fate and impact of marine debris (pp. 387-429). NOAA Tech. Memo. NMFS-SWFC-54. U. S. Dept. Commerce.

Collier, G., Hirsch, E. \& Kanarek, R. (1977). The operant revisited. Em W. K. Honig \& J. E. R. Staddon (Orgs.), Handbook of operant behavior (pp. 28-50). Englewood Cliffs, New Jersey: Prentice-Hall.

Dawkins, R. (1995). God's utility function. Scientific American, 273, 62-67.

Dobzhansky, T. (1973). Nothing in biology makes sense except in the light of evolution. The American Biology Teacher, 35, 125-129.

Dubois, M., Le Pendu, Y., Siciliano, G. \& Moinard, C. (1997). L'autre de l'animal dans le cadre d'une approche phénoménologique. Em G. Theraulaz \& F. Spitz (Orgs.), Auto-organisation et comportement (pp. 4959). Paris: Hermès.

Dubois, M., Sampaio, E., Gerard, J. F., Quenette, P. Y. \& Muniz, J. (2000). Location-specific responsiveness to environmental perturbations in Wedge-capped capuchin (Cebus olivaceus). International Journal of Primatology, 21, 85-102.

Fresneau, D. (1985). Individual foraging and path fidelity in a Ponerine ant. Insectes Sociaux, 32, 109-116.

Gallistel, C. R. (1993). The organization of learning. Cambridge: MIT Press.

Gerard, J. F., Dubois, M., Le Pendu, Y., Guilhem, C. \& Mechkour, F. (1997). Mondes émergents et évolution des systèmes vivants. Em G. Theraulaz \& F. Spitz (Orgs.), Auto-organisation et comportement (pp. 235-251). Paris: Hermès.

Goodwin, B. C. (1994). How the leopard changed its spots. The evolution of complexity. New York: Charles Scribner's sons. 
Gould, S. J. \& Lewontin, R. C. (1979). The spandrels of San Marco and the Panglossian paradigm: a critique of the adaptationist programme. Proceedings of the Royal Society of London Series B-Biological Sciences, 205, 581-598.

Gould, S. J. \& Eldredge, N. (1993). Punctuated equilibrium comes of age. Nature, 366, 223-227.

Held, R. \& Hein, A. (1963). Movement-produced stimulation in the development of visually guided behavior. Journal of Comparative \& Physiological Psychology, 56, 872 - 876.

Held, R. (1965). Plasticity in sensory-motor systems. Scientific American, 213, 84-94.

Hinde, R. A. \& Fisher, J. (1951). Further observations on the opening of milk bottles by birds. British Birds, 54, 393-396.

Jacob, F. (1981). Le jeu des possibles. Paris: Fayard.

Janis, C. M. \& Wilhem, P. B. (1993). Were there mammalian pursuits predators in the tertiary? Dances with wolf avatars. Journal of Mammalian Evolution, 1, 103-125.

Johnston, T. D. (1982). Selective costs and benefits in the evolution of learning. Advances in Studies of Behavior, 12, 65-106.

Kauffman, S. A. (1993). The origins of order. Self-organization and selection in evolution. Oxford: Oxford University Press.

Kawai, M. (1965). Newly-acquired pre-cultural behavior of the natural troop of Japanese monkeys on Koshima islet. Primates, 6, 1-30.

Krebs, J. R. \& Davies, N. B. (1981). An introduction to behavioural ecology. Oxford: Blackwell.

Lefebvre, L. (1995). Culturally-transmitted feeding-behavior in primates. Evidence for accelerating learning rates. Primates, 36, 227-239.

Lewontin, R. (1983). The organism as the subject and object of evolution. Scientia, 118, 65-82.
Maturana, H. \& Varela, F. (1987). The tree of knowledge. The biological roots of buman understanding. Boston: New Science Library.

McGrew, W. C. (1998). Culture in non-human primates? Annual Review of Anthropology, 27, 301-328

Merleau-Ponty, M. (1995). La nature. Cours du collège de France. Paris: Seuil.

Mrosovsky, N. (1981). Plastic jellyfish. Marine Turtle Newsletter, 17, 5-7.

Raup, D. M. (1992). Extinction. Bad genes or bad luck? New York: W.W. Norton $\&$ Co.

Staddon, J. E. R. (Org.). (1980). Limits to action: The allocation of individual behavior. New York: Academic Press.

Stewart, J. (1993). Introduction. Intellectica, 16, 7-20.

van Valen, F. (1973). A new evolutionary law. Evolution Theory, 1, 1-30.

Varela, F. J. (1979). Principles of biological autonomy. New York: Elsevier.

Varela, F., Thompson, E. \& Rosch, E. (1991). The embodied mind. Cognitive science and buman experience. Cambridge, Massachusetts: MIT Press.

Visalberghi, E. \& Fragaszy, D. (1990). Food-washing behavior in tufted capuchin monkeys (Cebus apella) and crabeating macaques (Macaca fascicularis). Animal Behaviour, 40, 829-836.

von Uexküll, J. (1956). Mondes animaux et monde bumain. Théorie de la signification. Paris: Gonthier.

Vrba, E. S. (1992). Mammals as a key to evolutionary theory. Journal of Mammalogy, 73, 1-28.

Whiten, A. (2000). Primate culture and social learning. Cognitive Science, $24,477-508$.

Recebido: 06/01/2000

Revisado: 05/03/2001

Aceite Final: 08/04/2001

Sobre os autores

Michel Jean Dubois é Psicólogo e Etólogo, Pesquisador do CNPq, Doutor em Ciências do Comportamento e Neurociências Cognitivas pela Universidade de Toulouse III (França). Professor da Pos-Graduação em Teoria e Pesquisa do Comportamento da Universidade Federal do Pará.

Yvonnick Le Pendu é Etólogo, Pesquisador do CNPq, Doutor em Ciências do comportamento e Neurociências Cognitivas pela Universidade de Toulouse III (França). Professor da Pós-Graduação em Teoria e Pesquisa do Comportamento da Universidade Federal do Pará.

Jean-François Gerard é Etólogo, Pesquisador do Instituto Nacional da Pesquisa Agronômica (INRA), França

Elineuza Sampaio é Estudante de Graduação do Colegiado de Psicologia da Universidade Federal do Pará. 